\title{
Quadriceps wasting and physical inactivity in patients with COPD
}

\author{
Dinesh Shrikrishna*, Mehul Patel*, Rebecca J. Tanner*, John M. Seymour", \\ Bronwen A. Connolly", Zudin A. Puthucheary ", Simon L.F. Walsh*, \\ Susannah A. Bloch*, Paul S. Sidhu+, Nicholas Hart", Paul R. Kemp*, John Moxham*, \\ Michael I. Polkey*, ${ }^{\S}$ and Nicholas S. Hopkinson*, ${ }^{\star 5}$
}

ABSTRACT: Quadriceps weakness is an important complication of advanced chronic obstructive pulmonary disease (COPD) but few data exist concerning muscle bulk in early disease. We hypothesised that quadriceps bulk, measured by ultrasound rectus femoris cross-sectional area (USRF $\mathrm{CSA}_{\mathrm{A}}$, would be reduced in mild, as well as advanced, COPD compared with controls, and would correlate with physical activity.

161 patients with stable COPD and 40 healthy subjects had a measurement of USRF CSA $_{\text {and }}$ wore a multisensor armband to record physical activity.

USRF $_{\text {CSA }}$ was reduced in Global Initiative for Chronic Obstructive Lung Disease (GOLD) stage I patients compared with healthy subjects $(p=0.0002)$. Stage II-IV patients had reduced USRF $(p<0.0001)$ compared with controls but were not significantly different from those with stage I disease. Physical activity level was reduced in stage I $(p=0.002)$ and stage II-IV disease compared with controls. Using regression analysis, physical activity level was independently associated with USRF $_{C S A}$ in stage I $(p=0.01)$ but not stage II-IV disease, where residual volume to total lung capacity ratio was the only independent predictor of physical activity level.

Quadriceps wasting exists in patients with mild, as well as advanced, COPD, and is independently associated with physical inactivity in GOLD stage I disease. The identification of these patients may guide early lifestyle and therapeutic interventions.

KEYWORDS: Mild chronic obstructive pulmonary disease, skeletal muscle, ultrasound rectus femoris cross-sectional area

keletal muscle dysfunction is a wellrecognised extrapulmonary complication of chronic obstructive pulmonary disease (COPD), with loss of lean body mass identified as a key determinant of disability [1] and an independent predictor of mortality [2]. In particular, reduced quadriceps strength is associated with reduced exercise capacity [3], impaired quality of life [4], increased healthcare use [5] and mortality independent of airflow obstruction [6].

The mechanisms involved in the development of skeletal muscle weakness in COPD are likely to be multifactorial, with systemic factors, such as oxidative stress [7], thought to interact with the key local factor of muscle inactivity [8, 9] particularly in the lower limbs [10]. Objectively measured physical activity has been identified as a strong predictor of all-cause mortality in COPD [11], highlighting its importance in a "downward disease spiral" where progressive dyspnoea leads to reduced exercise capacity with subsequent muscle deconditioning and further inactivity [12].

Quadriceps weakness has recently been observed in the absence of severe airflow obstruction in COPD [13], and there are data to suggest a reduction in physical activity in Global Initiative for Chronic Obstructive Lung Disease (GOLD) stage I patients [14]. Despite the potential rationale for muscle wasting in mild disease, few data exist on reduced quadriceps bulk in this patient group. Mid-thigh cross-sectional area measured by computed tomography (CT) has been shown to predict mortality in moderate-severe COPD [15]; however, the ionising radiation exposure makes this

Earn CME accreditation by answering questions about this article. You will find these at the back of the printed copy of this issue or online at www.erj.ersjournals.com/misc/cmeinfo.xhtml

This article has supplementary material available from www.erj.ersjournals.com

AFFILIATIONS

*National Heart and Lung Institute, NIHR Respiratory Biomedical Research Unit, Royal Brompton and Harefield NHS Foundation Trust and Imperial College London,

\# Dept of Asthma, Allergy and Respiratory Science, Division of Asthma, Allergy and Lung Biology, King's College London,

'Guy's and St Thomas' NHS Foundation Trust and King's College London, NIHR Comprehensive Biomedical Research Centre, and ${ }^{+}$Dept of Radiology, King's College Hospital, London, UK

${ }^{\S}$ These authors contributed equally.

CORRESPONDENCE

D. Shrikrishna

NIHR Respiratory Biomedical

Research Unit of Royal Brompton and Harefield NHS Foundation Trust and Imperial College London Fulham Road SW3 6NP UK E-mail: dinesh.shrikrishna@nhs.net

Received:

Oct 022011

Accepted after revision: Feb 012012 First published online: Feb 232012 
method of imaging undesirable, particularly in mild disease. Magnetic resonance imaging (MRI) has also been used as a thigh muscle imaging modality in COPD [16] but the accessibility and expense of this tool prohibit its adoption in the wider COPD population.

Ultrasound rectus femoris cross-sectional area $\left(\mathrm{USRF}_{\mathrm{CSA}}\right)$ is a radiation-free measure of muscle bulk that relates to quadriceps strength in COPD but is effort independent [17]. We hypothesised that quadriceps wasting measured by USRF $\mathrm{CSA}_{\mathrm{A}}$ would be observed in mild, as well as advanced, COPD compared with healthy, age-matched subjects, and that this would correlate with daily physical activity levels.

\section{METHODS}

\section{Patients and study design}

This cross-sectional study was approved by the Joint University College London Committees on the Ethics of Human Research (Committee Alpha) and the Ethics Committee of the Royal Brompton and Harefield NHS Foundation Trust (London, UK). All participants provided written informed consent. The COPD patients were recruited through outpatient clinics at the Royal Brompton Hospital, King's College and St Thomas' Hospitals (all London), and through public events conducted on World COPD Day and World No Tobacco Day. The period of recruitment was from August 2009 to August 2011. COPD patient diagnosis was based on UK National Institute for Health and Clinical Excellence guidelines [18] with severity defined using GOLD stage classification. Subjects within 1 month of an exacerbation or with a significant comorbidity including cardiac failure, neurological disease or rheumatoid arthritis that limited muscle function or activity level were excluded. Healthy, agematched controls were recruited by advertisement in local newspapers.

\section{Ultrasound rectus femoris cross-sectional area}

Measurement of quadriceps rectus femoris cross-sectional area was made by ultrasound using a technique previously described by SEYMOUR et al. [17]. B-mode ultrasonography was used with an 8-MHz, 7-cm linear array transducer (PLF 805 ST; Toshiba Medical Systems, Crawley, UK). Two trained operators (D. Shrikrishna and M. Patel) performed the ultrasound examinations. The patient was in a supine position with the rested leg supported in passive extension. An anatomical landmark was found at three-fifths of the distance along a line from the anterior superior iliac spine to the superior patella border. The transducer was positioned in the transverse plane and orientated so that the entire rectus femoris cross-sectional area could be visualised onscreen. This image was frozen (fig. 1) and the echogenic line representing the fascia around the rectus femoris was outlined manually by the operator. Rectus femoris cross-sectional area was calculated using a planimetric technique (Nemio; Toshiba Medical Systems) and the average of three consecutive measurements was taken.

\section{Quadriceps strength and fat-free mass measurements}

A volitional measurement of quadriceps maximum voluntary contraction (QMVC) was made using the technique described by EDWARDS et al. [19]. Subjects sat on a modified chair with their knee fixed at $90^{\circ}$ and performed at least three sustained maximal isometric quadriceps contractions. QMVC was taken as the highest tension sustained for $1 \mathrm{~s}$.

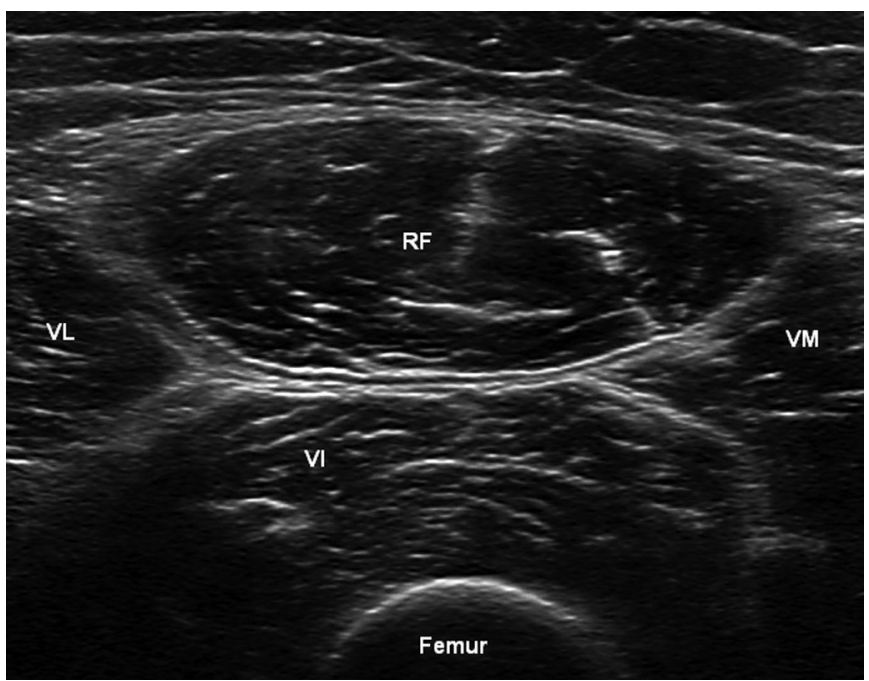

FIGURE 1. Ultrasound assessment of the rectus femoris in the transverse plane. RF: rectus femoris; VL: vastus lateralis; VM: vastus medialis; VI: vastus intermedius.

Fat-free mass index (FFMI) was determined by bioelectrical impedance analysis at $50 \mathrm{kHz}$ (BodyStat QuadScan 4000; BodyStat, Douglas, UK) using a disease-specific regression equation [20]. Measurements of the impedance at $5 \mathrm{kHz}(Z 5)$ and $200 \mathrm{kHz}($ Z200) also allowed calculation of the bioelectrical impedance ratio $(Z 200 / Z 5)$. Health-related quality of life was determined using the St George's Respiratory Questionnaire and breathlessness was recorded using the Medical Research Council (MRC) dyspnoea score. A detailed description of techniques has been included in the online supplementary material.

\section{Physical activity monitoring}

Daily physical activity was recorded using a multisensor biaxial accelerometer armband (SenseWear; BodyMedia, Pittsburgh, PA, USA) as previously described by WATZ et al. [9]. The armband incorporates physiological sensors that quantify galvanic skin response, heat flux and skin temperature to estimate energy expenditure and has been previously validated against indirect calorimetry in COPD patients [21, 22] and against the doubly labelled water technique in healthy subjects [23]. The physical activity level (PAL) was calculated using total energy expenditure (TEE) and sleep energy expenditure as a surrogate for resting energy expenditure (REE) (PAL=TEE/ REE). Daily step count and PAL were measured over six consecutive days incorporating one weekend and four weekdays. A valid physical activity assessment was defined as $\geqslant 21.5 \mathrm{~h}(90 \%)$ wearing time a day on at least 5 days. Data were downloaded and analysed using SenseWear Professional software (version 6.1).

\section{Pulmonary function testing}

Pulmonary function testing was undertaken by the Royal Brompton Hospital Lung Function Department. Spirometry, plethysmographic lung volumes, carbon monoxide diffusing capacity (CompactLab system; Jaeger, Wurzburg, Germany) and arterial blood gases were determined in accordance with European Respiratory Society/American Thoracic Society recommendations [24-26]. 


\section{Data and statistical analysis}

Data are presented as mean \pm SD with accompanying p-values and analysis was performed using StatView 5.0 (Abacus Concepts, Inc., Berkeley, CA, USA). Between-group comparisons used ANOVA with post hoc correction for more than two groups. Relationships between $\mathrm{USRF}_{\mathrm{CSA}}$, quadriceps strength, FFMI, impedance ratio, daily physical activity and pulmonary function were analysed using univariate and multivariate linear regression models. Figure construction was performed with GraphPad Prism (version 5.0; GraphPad Software, San Diego, CA, USA).

\section{RESULTS}

201 subjects, comprising 161 stable COPD patients and 40 healthy, age-matched volunteers, participated in the study. Baseline characteristics are shown in table 1. Of these, 154 subjects (123 COPD patients and 31 healthy participants) completed a valid physical activity assessment. Out of the remaining 47 subjects, 14 did not complete a valid period of assessment, four subjects declined to participate in this part of the study and the remainder were not given an armband for logistical reasons (e.g. armband availability and subject's distance from hospital). In those subjects participating in activity monitoring, a valid period of assessment was reached in $92 \%$ (154 out of 168 subjects). Average wearing time per day was $98 \%$ and did not significantly differ across groups (table 2 ).

\section{USRF $_{C S A}$ and quadriceps strength in COPD (stage I-IV) and healthy subjects}

$\mathrm{USRF}_{\mathrm{CSA}}$ and quadriceps strength (QMVC) were reduced in all GOLD stages compared with controls (table 2, and figs 2 and 3). There were no significant differences in $U_{S R F} F_{C A}$ or QMVC across GOLD stages, except between QMVC in stage I and IV $(\mathrm{p}<0.02)$. In COPD patients, forced expiratory volume in $1 \mathrm{~s}$ (FEV1) \% predicted showed no association with USRF $\mathrm{CSA}_{\mathrm{A}}$ and a weak association with QMVC $(r=0.2, p=0.03) . U^{2} R_{C S A}$ had a linear relationship with QMVC in COPD subjects $(r=0.6$, $\mathrm{p}<0.0001$ ) (fig. S1). QMVC was also significantly associated with FFMI $(\mathrm{r}=0.54, \mathrm{p}<0.0001)$ and $\mathrm{Z} 200 / \mathrm{Z} 5 \quad(\mathrm{r}=-0.54$, $\mathrm{p}<0.0001$ ) in COPD (fig. S2). A multiple regression model was used to predict $\mathrm{USRF}_{\mathrm{CSA}}$ in all COPD subjects incorporating the significant independent variables from the univariate analysis (table S1). Sex $(r=0.27, p=0.003)$, QMVC $(r=0.24$, $\mathrm{p}=0.01)$, residual volume $(\mathrm{RV}) /$ total lung capacity (TLC) ratio

TABLE 1 Baseline characteristics of chronic obstructive pulmonary disease (COPD) and control subjects

\begin{tabular}{|c|c|c|c|c|c|c|}
\hline & \multirow[t]{2}{*}{ Controls } & \multicolumn{4}{|c|}{ COPD } & \multirow[t]{2}{*}{ p-value } \\
\hline & & GOLD I & GOLD II & GOLD III & GOLD IV & \\
\hline Subjects $n$ & 40 & 38 & 45 & 41 & 37 & \\
\hline Age yrs & $65 \pm 8$ & $67 \pm 9$ & $67 \pm 9$ & $67 \pm 9$ & $63 \pm 8$ & 0.17 \\
\hline Males/females $\mathbf{n}$ & $20 / 20$ & $19 / 19$ & $22 / 23$ & $22 / 19$ & $25 / 12$ & 0.45 \\
\hline $\mathrm{BMI} \mathbf{k g} \cdot \mathrm{m}^{-2}$ & $25.9 \pm 3.6$ & $26.5 \pm 4.8$ & $26.6 \pm 5.9$ & $25.2 \pm 4.5$ & $22.4 \pm 3.8$ & 0.0006 \\
\hline FFMI $\mathbf{k g} \cdot \mathrm{m}^{-2}$ & $17.8 \pm 2.1$ & $17.9 \pm 2$ & $17.7 \pm 2.7$ & $17.6 \pm 2.2$ & $16.2 \pm 1.9$ & 0.004 \\
\hline Smoking pack-yrs & $9.1 \pm 14.3$ & $28.1 \pm 22.2$ & $42 \pm 29.2$ & $50 \pm 26.2$ & $55.5 \pm 29.3$ & $<0.0001$ \\
\hline Current smokers \% & & 11 & 29 & 27 & 14 & 0.09 \\
\hline Outpatients ${ }^{\#} \%$ & & 47 & 60 & 66 & 89 & 0.001 \\
\hline Long-acting $\beta$-agonist \% & & 58 & 80 & 85 & 100 & $<0.0001$ \\
\hline Long-acting anticholinergic \% & & 42 & 71 & 83 & 97 & $<0.0001$ \\
\hline Inhaled corticosteroid \% & & 58 & 78 & 83 & 100 & $<0.0001$ \\
\hline Oral corticosteroid $\geqslant 5 \mathrm{mg} \cdot$ day $^{-1} \%$ & & 0 & 0 & 0 & 8 & 0.02 \\
\hline FEV $1 \%$ pred & $103.1 \pm 11.7$ & $90.8 \pm 8.8$ & $63.2 \pm 8.8$ & $39.4 \pm 5.5$ & $24 \pm 3.8$ & $<0.0001$ \\
\hline TL,Co \% pred & $89.3 \pm 17.1$ & $67.5 \pm 17.8$ & $58.1 \pm 14.7$ & $39.9 \pm 13.9$ & $26.6 \pm 9$ & $<0.0001$ \\
\hline RV/TLC \% & $34 \pm 4.6$ & $40.6 \pm 6.6$ & $46.6 \pm 8$ & $57.9 \pm 7.5$ & $64.7 \pm 6.9$ & $<0.0001$ \\
\hline IC L & $2.8 \pm 0.7$ & $2.7 \pm 0.8$ & $2.3 \pm 0.8$ & $1.9 \pm 0.6$ & $1.8 \pm 0.4$ & $<0.0001$ \\
\hline $\mathrm{Pa}, \mathrm{O}_{2} \mathrm{kPa}$ & $11.2 \pm 1.1$ & $10.6 \pm 1.5$ & $10.2 \pm 1.2$ & $9.1 \pm 1.2$ & $9.1 \pm 1.3$ & $<0.0001$ \\
\hline $\mathrm{Pa}, \mathrm{CO}_{2} \mathrm{kPa}$ & $5 \pm 0.6$ & $4.7 \pm 0.5$ & $5 \pm 0.4$ & $5.1 \pm 0.5$ & $5.4 \pm 0.6$ & $<0.0001$ \\
\hline MRC score ${ }^{\pi}$ & $1.1 \pm 0.3$ & $1.8 \pm 0.4$ & $2.5 \pm 0.9$ & $3.1 \pm 0.9$ & $3.6 \pm 0.9$ & $<0.0001$ \\
\hline \multicolumn{7}{|l|}{ SGRQ } \\
\hline Symptoms & & $29.4 \pm 24.8$ & $49.6 \pm 22.8$ & $50 \pm 23.7$ & $61.6 \pm 19.1$ & $<0.0001$ \\
\hline Activity & & $34.7 \pm 25$ & $58.1 \pm 23.9$ & $70.1 \pm 19.4$ & $84.5 \pm 11.5$ & $<0.0001$ \\
\hline Impacts & & $15.5 \pm 15.1$ & $29.9 \pm 17.4$ & $33.8 \pm 17.4$ & $48.4 \pm 18.1$ & $<0.0001$ \\
\hline Total & & $23.1 \pm 16.8$ & $41.1 \pm 17.9$ & $47.6 \pm 16.4$ & $61.5 \pm 13.8$ & $<0.0001$ \\
\hline
\end{tabular}

Data are presented as mean \pm SD, unless otherwise stated. GOLD: Global Initiative for Chronic Obstructive Lung Disease; BMI: body mass index; FFMI: fat-free mass index; FEV1: forced expiratory volume in $1 \mathrm{~s}$; \% pred: \% predicted; $T \mathrm{~L}, \mathrm{CO}$ : transfer factor of the lung for carbon monoxide; RV: residual volume; TLC: total lung capacity; IC: inspiratory capacity; $\mathrm{Pa}_{2} \mathrm{O}_{2}$ : arterial oxygen tension; $\mathrm{Pa}_{\mathrm{a}} \mathrm{CO}_{2}$ : arterial carbon dioxide tension; MRC: Medical Research Council; SGRQ: St George's Respiratory Questionnaire. " : any previous hospital clinic attendance; " : on a scale of 1-5. 


\begin{tabular}{|c|c|c|c|c|c|c|c|}
\hline \multirow[t]{3}{*}{ TABLE 2} & \multicolumn{7}{|c|}{$\begin{array}{l}\text { Quadriceps and physical activity measurements in chronic obstructive pulmonary disease (COPD) and control } \\
\text { subjects }\end{array}$} \\
\hline & & \multirow[t]{2}{*}{ Controls } & \multicolumn{4}{|c|}{ COPD } & \multirow[t]{2}{*}{ p-value } \\
\hline & & & GOLD I & GOLD II & GOLD III & GOLD IV & \\
\hline \multicolumn{2}{|c|}{ USRF $_{\mathrm{CSA}} \mathrm{mm}^{2}$} & $640 \pm 136$ & $530 \pm 116$ & $511 \pm 135$ & $504 \pm 122$ & $509 \pm 122$ & $<0.0001$ \\
\hline \multicolumn{2}{|c|}{ PAL } & $1.69 \pm 0.25$ & $1.56 \pm 0.16$ & $1.47 \pm 0.16$ & $1.4 \pm 0.12$ & $1.38 \pm 0.19$ & $<0.0001$ \\
\hline \multicolumn{2}{|c|}{ Armband wearing time $h \cdot d^{-1}{ }^{-1}$} & $23.57 \pm 0.28$ & $23.60 \pm 0.26$ & $23.64 \pm 0.37$ & $23.57 \pm 0.52$ & $23.61 \pm 0.39$ & 0.95 \\
\hline \multicolumn{2}{|c|}{$Z_{200 / Z 5}$} & $0.789 \pm 0.03$ & $0.791 \pm 0.03$ & $0.806 \pm 0.03$ & $0.816 \pm 0.03$ & $0.814 \pm 0.03$ & 0.0002 \\
\hline
\end{tabular}

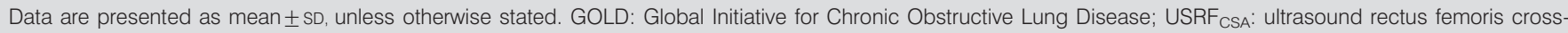
sectional area; QMVC: quadriceps maximal voluntary contraction; PAL: physical activity level; Z200: impedance at $200 \mathrm{kHz} ; \mathrm{Z}$ : impedance at $5 \mathrm{kHz}$.

$(\mathrm{r}=-0.28, \mathrm{p}=0.01)$, inspiratory capacity (IC) $(\mathrm{r}=0.20, \mathrm{p}=0.04)$ and FFMI $(r=0.19, p=0.04)$ were retained as independent predictors of USRF $\mathrm{CSA}_{\mathrm{C}}(\mathrm{r}=0.75, \mathrm{p}<0.0001)$. In a similar multiple regression model with QMVC as the dependent variable, only $\operatorname{USRF}_{\mathrm{CSA}}(\mathrm{r}=0.24, \mathrm{p}=0.02)$ and FFMI $(\mathrm{r}=0.25, \mathrm{p}=0.01)$ were retained as independent predictors of quadriceps strength in COPD $(\mathrm{r}=0.74, \mathrm{p}<0.0001)$. As sex was identified

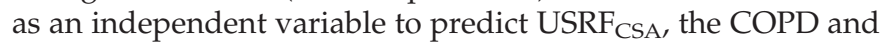
healthy subjects were separated into males and females (fig. S3). In both sexes, USRF CSA $_{\text {a }}$ was reduced in all GOLD stages compared with controls and there were no significant differences in USRF $_{C S A}$ across GOLD stages. Males $(n=108)$ had a significantly greater $U_{S R F} F_{C S A}$ compared with females $\left(\mathrm{n}=93 ; 597\right.$ versus $\left.470 \mathrm{~mm}^{2}, \mathrm{p}<0.0001\right)$.

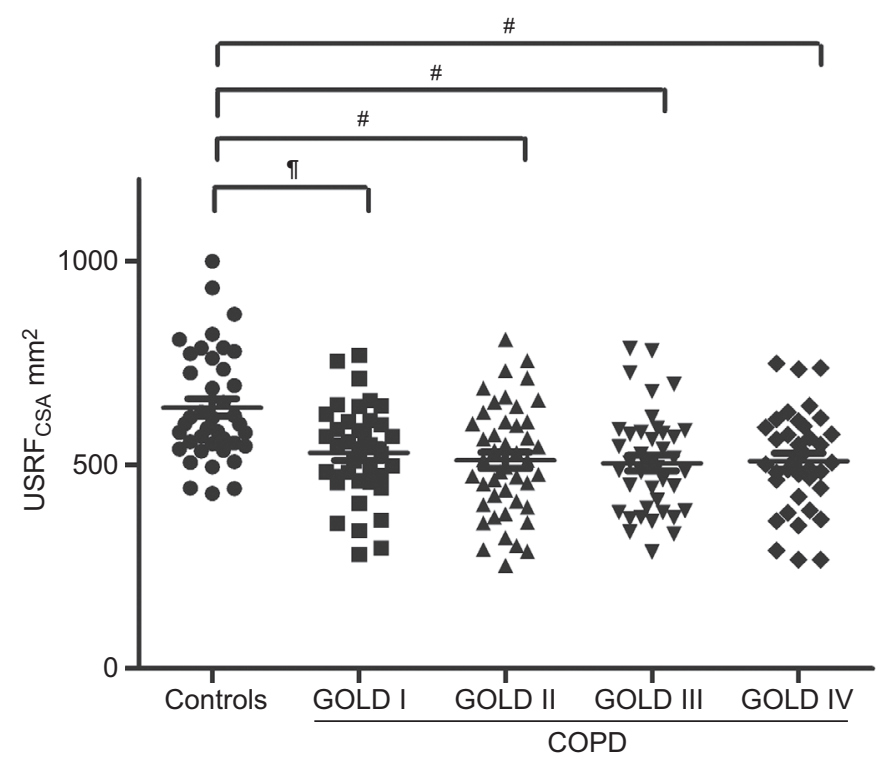

FIGURE 2. Ultrasound rectus femoris cross-sectional area (USRF $\mathrm{CSA}_{\mathrm{A}}$ ) versus Global Initiative for Chronic Obstructive Lung Disease (GOLD) stage in chronic obstructive pulmonary disease (COPD) patients and healthy controls. There was no significant difference between GOLD stages by ANOVA. Data are presented as mean \pm SEM. ${ }^{*}: p<0.0001 ;{ }^{\circ}: p=0.0002$.

\section{Relationship of daily physical activity with GOLD stage and USRF}

Daily physical activity was significantly reduced in all GOLD stages compared with healthy controls (figs 4 and 5). Mean group differences are shown in table 2. Daily physical activity showed a linear relationship with $\mathrm{FEV} 1 \%$ pred (steps $\mathrm{r}=0.6$, PAL $\mathrm{r}=0.4 ; \mathrm{p}<0.0001$ ) and $\mathrm{USRF}_{\mathrm{CSA}}$ (steps $\mathrm{r}=0.3, \mathrm{p}=0.002$; PAL $r=0.2, p<0.05)$ in all COPD patients. In stage I disease, a multiple linear regression model to predict USRF CSA $_{\text {was }}$ used incorporating the significant independent variables from the univariate analysis (table S2). PAL was the only variable retained as an independent predictor of $\mathrm{USRF}_{\mathrm{CSA}}$ in stage I disease $(r=0.76, p=0.01)$. In a similar regression analysis in stage II-IV disease, sex $(r=0.29, p=0.01), \quad R V / T L C$ ratio

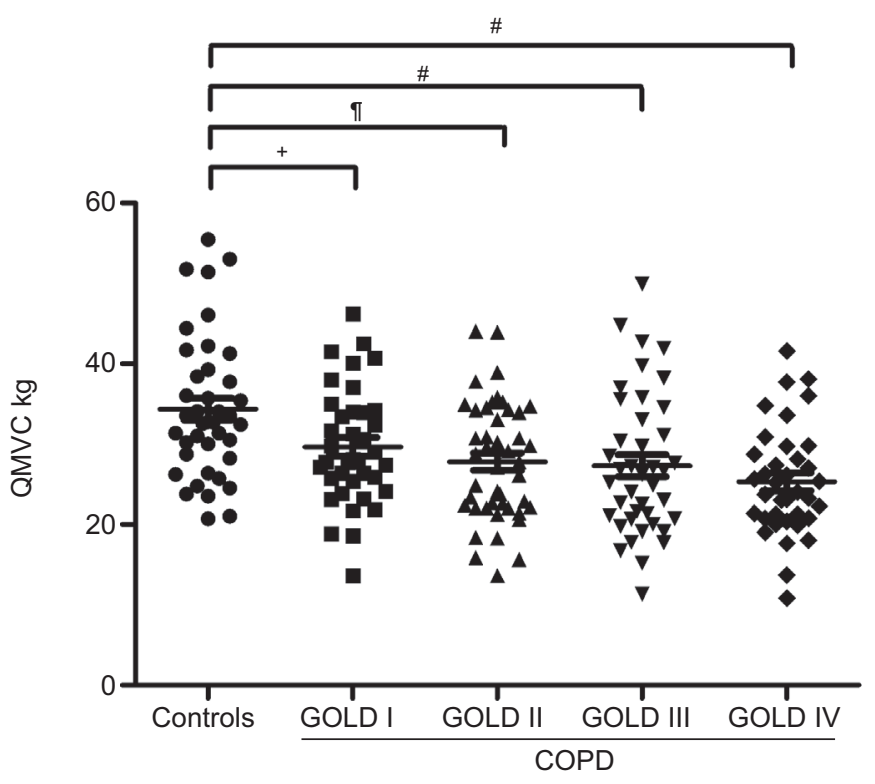

FIGURE 3. Quadriceps maximal voluntary contraction (QMVC) versus Global Initiative for Chronic Obstructive Lung Disease (GOLD) stage in chronic obstructive pulmonary disease (COPD) and healthy controls. No significant differences were found between GOLD stages by ANOVA, except I and IV ( $p<0.02)$. Data are presented as mean \pm SEM. ${ }^{\#}: p<0.0001 ;{ }^{\bullet}: p=0.0002 ;^{+}: p=0.009$. 


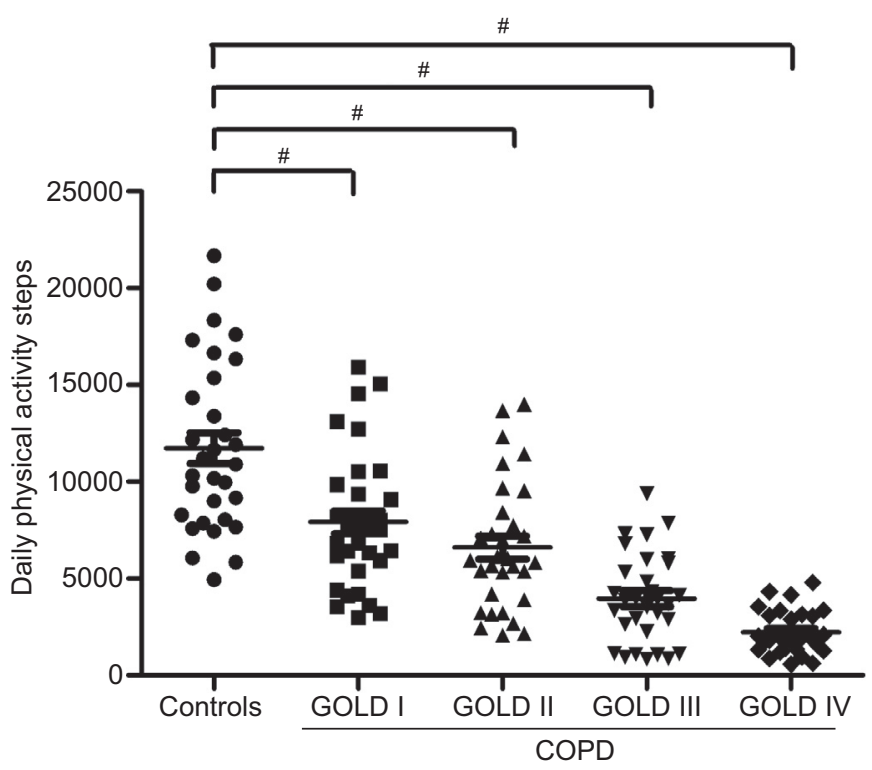

FIGURE 4. Daily physical activity (steps) versus Global Initiative for Chronic Obstructive Lung Disease (GOLD) stage in chronic obstructive pulmonary disease (COPD) patients and healthy controls. By ANOVA, significant differences were observed between stages I and III, and I and IV ( $p<0.0001)$, II and III $(p=0.002)$, II and IV $(p<0.0001)$, and III and IV $(p=0.03)$. Data are presented as mean \pm SEM. ${ }^{*}: p<0.0001$.

$(\mathrm{r}=-0.28, \mathrm{p}=0.01)$ and IC $(\mathrm{r}=0.29, \mathrm{p}=0.02)$, but not physical activity, were retained as independent predictors of $\mathrm{USRF}_{\mathrm{CSA}}$ $(\mathrm{r}=0.78, \mathrm{p}<0.0001)$.

In a separate multiple linear regression model to predict physical activity in stage II-IV COPD, when incorporating the univariate correlates (table S3), RV/TLC ratio was retained over FEV1 \% pred as the only independent variable associated with physical activity level $(\mathrm{r}=-0.23, \mathrm{p}=0.03)$. Using this model in stage I COPD, USRF ${ }_{C S A}$, but not QMVC, was retained as the only independent correlate with physical activity level $(\mathrm{r}=0.64, \mathrm{p}=0.005)$.

\section{Ultrasound validity and reproducibility}

A subset of 80 COPD patients had an additional mid-thigh CT scan (detailed in the online supplementary material) with USRF $_{C S A}$ correlating significantly with mid-thigh $\mathrm{CT}_{\mathrm{CSA}}(\mathrm{r}=0.7$, $\mathrm{p}<0.0001)$ and rectus femoris $\mathrm{CT}_{\mathrm{CSA}}(\mathrm{r}=0.7, \mathrm{p}<0.0001)$. Further data on inter-occasion and interobserver variability (fig. S4), ultrasound measurement of the pennation angle and use of different measurement points are described in table S4.

\section{DISCUSSION}

Using USRF CSA $_{\text {A }}$ we found quadriceps wasting in mild, as well as advanced, COPD judged by GOLD stage. A $17 \%$ reduction in mean USRF $\mathrm{CSA}_{\mathrm{C}}$ was observed in stage I patients compared with a healthy, age-matched group with a similar whole-body FFMI. The study also identified an independent association between physical activity level and $\mathrm{USRF}_{\mathrm{CSA}}$ in stage I disease, with this group significantly less active when compared to healthy subjects.

\section{Significance of the findings}

A recent study incorporating a large UK and Dutch COPD cohort [13] identified a $28 \%$ prevalence of quadriceps weakness

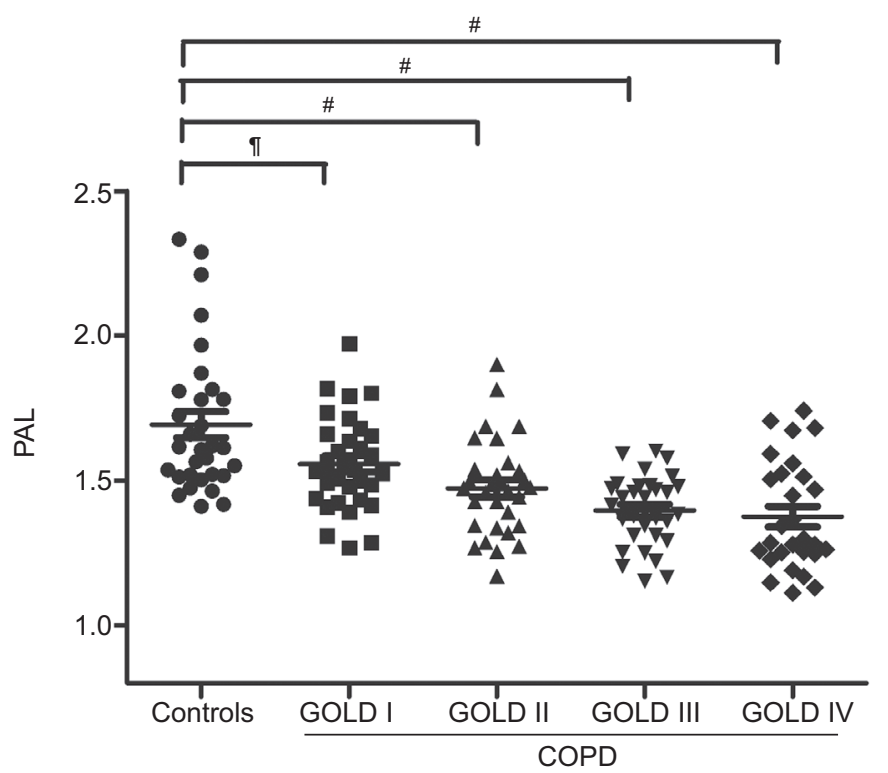

FIGURE 5. Physical activity level (PAL) versus Global Initiative for Chronic Obstructive Lung Disease (GOLD) stage in chronic obstructive pulmonary disease (COPD) subjects and healthy controls. By ANOVA, significant differences were observed between stages I and III $(p=0.0006)$, I and IV $(p=0.0002)$, and II and IV $(p=0.04)$. Data are presented as mean \pm SEM. ${ }^{*}: p<0.0001 ; ": p=0.002$.

in stage I patients and supports our contention that reduced quadriceps muscle bulk is present in early disease. The simple and effort-independent nature of ultrasound makes it an attractive test for detecting patients who may benefit from early intervention, and avoids the need for strength measurements using research-based equipment or less reliable portable handheld devices, both of which are inherently subject to volitional influence. Interestingly, in our study, USRF $\mathrm{CSA}_{\mathrm{A}}$, rather than quadriceps strength, was independently associated with physical activity in stage I COPD, implying that this effortindependent measure of quadriceps size may be a more sensitive parameter for investigating the relationship between lower limb muscle dysfunction and physical activity in patients with mild disease. This is particularly important as new COPD phenotypes are established requiring evaluation and as therapeutic interventions focus on physical activity promotion [27].

The finding of reduced daily physical activity in stage I COPD compared to healthy subjects is supported by previous data from WATZ et al. [14] showing a reduction in activity in GOLD stage I patients compared with a chronic bronchitis (formerly GOLD stage 0) cohort. Although their observed reduction did not reach statistical significance, the comparison was not made with a healthy control group as in our current study. There have been very few other studies investigating physical activity in mild-moderate COPD patients. A multicentre study recently found a reduction in early disease from stage II COPD onwards compared with healthy controls; however, this study had a small number of patients $(n=9)$ with GOLD stage I disease [28]. There is evidence to suggest that symptomatic GOLD stage I patients experience dynamic hyperinflation associated with dyspnoea during exercise compared with control subjects [29]. GOLD stage I patients in our study had a significantly higher MRC dyspnoea score than healthy controls 
and this may therefore provide a mechanism for the initial reduction in physical activity seen early in the disease process.

The finding of reduced physical activity in stage I COPD and its association with $\mathrm{USRF}_{\mathrm{CSA}}$ allows discussion of a potential mechanism for reduced quadriceps bulk in mild disease. Stage II-IV patients also demonstrated a reduction in quadriceps bulk compared to control subjects but this was not significantly different from the stage I group, suggesting that a threshold level of physical inactivity, reached early in the disease process, triggers the depletion in muscle bulk. There is evidence from the Copenhagen City Heart Study [30] and elsewhere [31] that physical inactivity may in fact precede the occurrence of airflow obstruction, and that it is a significant aetiological factor for the development of COPD. In addition, recent data have highlighted physical activity as a strong predictor of all-cause mortality in COPD [11], emphasising its importance in this patient group, although that study compared activity to measures of whole-body FFM and BMI, rather than quadriceps muscle bulk or strength. Consistent with previous work [14, 32], we found that lung function is associated with the level of physical activity in COPD and RV/TLC ratio, rather than FEV1 $\%$ pred, is an independent predictor of physical activity level in

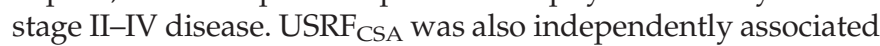
with RV/TLC ratio and IC, but not FEV1 \% pred, highlighting that although FEV1 can be used for classifying the severity of airflow obstruction [33] it does not reflect the true severity of the disease. There is increasing evidence to support measures of gas trapping and thoracic distension as better indicators of disease severity than airflow obstruction in COPD [34, 35]. Our finding

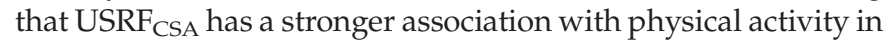
the mild, compared with the more advanced, group suggests that these pulmonary factors are more limiting to activity in moderate-severe patients, compared with those with mild COPD where the association between muscle wasting and inactivity is more pronounced.

Importantly, in our study, whole-body measurement of FFMI was similar in controls and patients with mild disease, although USRF $_{\text {CSA }}$ was reduced, supporting local disuse as a key factor. Disuse may also increase susceptibility to systemic factors, particularly the effects of smoking, which is in itself known to be associated with skeletal muscle oxidative stress [36] and quadriceps weakness [37]. It should be noted, however, that inactivity may act as a significant confounder when observing quadriceps dysfunction as an effect of smoking. Further studies are needed to explore whether the fibre type switch from oxidative type I fibres to anaerobic type II fibres reported in advanced COPD [38] occurs earlier in the disease process as a consequence of physical inactivity interacting with systemic effects.

Of additional note in this study, Z200/Z5 has been found to show strong associations with $\mathrm{USRF}_{\mathrm{CSA}}$ and quadriceps strength in COPD patients; univariate correlates are shown in table S5). At the low frequency $(5 \mathrm{kHz})$, current does not penetrate cell membranes; however, at the high frequency $(200 \mathrm{kHz})$, both intracellular and extracellular spaces are penetrated. Therefore, the ratio of the bioelectrical impedance at these frequencies $(Z 200 / Z 5)$ is thought to give an index of separation of the two compartments, extracellular and total body water. In contrast to the use of bioelectrical impedance analysis to calculate fat-free mass using regression equations that may include height, weight and sex, the impedance ratio is based on direct measurements. The ratio may be influenced by acute or chronic illness, with a higher value already shown to be associated with greater disease severity in patients with heart failure [39]. Z200/Z5 therefore warrants further investigation as a noninvasive biomarker in COPD.

\section{Critique of the method}

Although this study cannot establish causation, the association between physical inactivity and depletion in muscle bulk in mild disease is strongly suggestive of a mechanistic link. The potential role of $U_{S R F} F_{C S}$ in detecting longitudinal change and response to intervention in COPD remains to be investigated.

The patients recruited in this cross-sectional study are a combination of those seen in hospital outpatients as well as those from the community setting who are not seen in secondary care (table 1). Importantly, the patients with mild disease in this study had very similar physical activity levels to the GOLD stage I cohort studied by WATZ et al. [14], suggesting that our group is representative of the general COPD population.

The strong correlation of USRF $\mathrm{CSA}_{\mathrm{A}}$ with both mid-thigh and rectus femoris CT measurements supports the use of the rectus femoris as a representation of quadriceps bulk and confirms our initial findings in a small cohort of COPD patients [17]. Furthermore, interobserver and inter-occasion agreement for USRF $_{\text {CSA }}$ measurement in this study were similar to that for other muscle ultrasound imaging [40]. The key areas for measurement error, in our experience, result from operator accuracy of probe position in relation to surface anatomy and inaccurate cursor outline of the acquired rectus femoris image, both of which may be related to operator training and experience. CT and MRI modalities have been shown to have an advantage over ultrasound in serial measurements, which is probably to relate to use of bony landmarks for measurement position in comparison to the use of surface anatomy. However, a randomised controlled trial using electrical muscle stimulation to reduce muscle wasting in the intensive care unit setting has shown that ultrasound measurement of the quadriceps has strong potential as a bedside imaging modality for identifying serial changes in muscle bulk following intervention [41].

In relation to the objective measurements of activity in this study, both daily step count and PAL were used as measures of daily physical activity, although the SenseWear armband monitor has been shown to underestimate step count at slow walking speeds [22]. This may account for differences in the statistical strength of these activity variables when incorporated into the regression analyses. Importantly, the study participants showed good compliance with the SenseWear armband, in keeping with recent data on the wearing time of this device in COPD and healthy subjects [42].

\section{Conclusion}

In summary, this study has shown that quadriceps wasting identified by USRF $\mathrm{CSA}_{\text {A }}$ exists in patients with mild, as well as advanced, COPD. Quadriceps bulk was associated with daily physical activity, independent of airflow limitation, in GOLD stage I disease. Our data suggest that, rather than being an endstage phenomenon, quadriceps wasting occurs in a substantial 
minority of COPD patients including those with early disease. USRF $_{\text {CSA }}$ has potential as a physiological biomarker in COPD, and the identification of these patients may guide early lifestyle and therapeutic interventions.

\section{SUPPORT STATEMENT}

The study was funded by the UK Medical Research Council (MRC) (grant G0701628). N.S. Hopkinson is a Higher Education Funding Council for England Clinical Senior Lecturer. M.I. Polkey is partfunded by the NIHR Respiratory Biomedical Research Unit of the Royal Brompton Hospital and Imperial College London. J.M. Seymour was funded by the British Lung Foundation (grant PO4/8). S.A. Bloch is a MRC Clinical Fellow (grant G0901955).

\section{STATEMENT OF INTEREST}

A statement of interest for M.I. Polkey can be found at www.erj. ersjournals.com/site/misc/statements.xhtml

\section{ACKNOWLEDGEMENTS}

The authors wish to thank A.K. Boutou (NIHR Respiratory Biomedical Research Unit, Royal Brompton and Harefield NHS Foundation Trust and Imperial College, London, UK) for her statistical input in the data analysis and are grateful to the members of the Lung Function Department at the Royal Brompton Hospital (London) for their testing of study participants. In particular, the authors wish to thank all the patients and healthy volunteers who participated in this study.

\section{REFERENCES}

1 Skeletal muscle dysfunction in chronic obstructive pulmonary disease. A statement of the American Thoracic Society and European Respiratory Society. Am J Respir Crit Care Med 1999; 159: S1-S40.

2 Schols AM, Broekhuizen R, Weling-Scheepers CA, et al. Body composition and mortality in chronic obstructive pulmonary disease. Am J Clin Nutr 2005; 82: 53-59.

3 Gosselink R, Troosters T, Decramer M. Peripheral muscle weakness contributes to exercise limitation in COPD. Am J Respir Crit Care Med 1996; 153: 976-980.

4 Simpson K, Killian K, McCartney N, et al. Randomised controlled trial of weightlifting exercise in patients with chronic airflow limitation. Thorax 1992; 47: 70-75.

5 Decramer M, Gosselink R, Troosters T, et al. Muscle weakness is related to utilization of health care resources in COPD patients. Eur Respir J 1997; 10: 417-423.

6 Swallow EB, Reyes D, Hopkinson NS, et al. Quadriceps strength predicts mortality in patients with moderate to severe chronic obstructive pulmonary disease. Thorax 2007; 62: 115-120.

7 Barreiro E, Peinado VI, Galdiz JB, et al. Cigarette smoke-induced oxidative stress: A role in chronic obstructive pulmonary disease skeletal muscle dysfunction. Am J Respir Crit Care Med 2010; 182 477-488

8 Pitta F, Troosters T, Spruit MA, et al. Characteristics of physical activities in daily life in chronic obstructive pulmonary disease. Am J Respir Crit Care Med 2005; 171: 972-977.

9 Watz H, Waschki B, Boehme C, et al. Extrapulmonary effects of chronic obstructive pulmonary disease on physical activity: a cross-sectional study. Am J Respir Crit Care Med 2008; 177: 743-751.

10 Man WDC, Soliman MGG, Nikoletou D, et al. Non-volitional assessment of skeletal muscle strength in patients with chronic obstructive pulmonary disease. Thorax 2003; 58: 665-669.

11 Waschki B, Kirsten A, Holz O, et al. Physical activity is the strongest predictor of all-cause mortality in patients with COPD: a prospective cohort study. Chest 2011; 140: 331-342.

12 Polkey MI, Moxham J. Attacking the disease spiral in chronic obstructive pulmonary disease. Clin Med 2006; 6: 190-196.
13 Seymour JM, Spruit MA, Hopkinson NS, et al. The prevalence of quadriceps weakness in COPD and the relationship with disease severity. Eur Respir J 2010; 36: 81-88.

14 Watz H, Waschki B, Meyer T, et al. Physical activity in patients with COPD. Eur Respir J 2009; 33: 262-272.

15 Marquis K, Debigare R, Lacasse Y, et al. Midthigh muscle crosssectional area is a better predictor of mortality than body mass index in patients with chronic obstructive pulmonary disease. Am J Respir Crit Care Med 2002; 166: 809-813.

16 Mathur S, Takai KP, Macintyre DL, et al. Estimation of thigh muscle mass with magnetic resonance imaging in older adults and people with chronic obstructive pulmonary disease. Phys Ther 2008; 88: 219-230.

17 Seymour JM, Ward K, Sidhu PS, et al. Ultrasound measurement of rectus femoris cross-sectional area and the relationship with quadriceps strength in COPD. Thorax 2009; 64: 418-423.

18 National Institute for Health and Clinical Excellence. CG101 Chronic obstructive pulmonary disease (update): full guideline. http://guidance.nice.org.uk/CG101/Guidance Date last accessed: August 22, 2012. Date last updated: May 30, 2012.

19 Edwards RH, Young A, Hosking GP, et al. Human skeletal muscle function: description of tests and normal values. Clin Sci Mol Med 1977; 52: 283-290.

20 Steiner MC, Barton RL, Singh SJ, et al. Bedside methods versus dual energy X-ray absorptiometry for body composition measurement in COPD. Eur Respir J 2002; 19: 626-631.

21 Patel SA, Benzo RP, Slivka WA, et al. Activity monitoring and energy expenditure in COPD patients: a validation study. COPD 2007; 4: 107-112.

22 Hill K, Dolmage TE, Woon L, et al. Measurement properties of the SenseWear armband in adults with chronic obstructive pulmonary disease. Thorax 2010; 65: 486-491.

23 St-Onge M, Mignault D, Allison DB, et al. Evaluation of a portable device to measure daily energy expenditure in free-living adults. Am J Clin Nutr 2007; 85: 742-749.

24 Miller MR, Hankinson J, Brusasco V, et al. Standardisation of spirometry. Eur Respir J 2005; 26: 319-338.

25 Macintyre N, Crapo RO, Viegi G, et al. Standardisation of the single-breath determination of carbon monoxide uptake in the lung. Eur Respir J 2005; 26: 720-735.

26 Wanger J, Clausen JL, Coates A, et al. Standardisation of the measurement of lung volumes. Eur Respir J 2005; 26: 511-522.

27 Casaburi R. Activity promotion: a paradigm shift for chronic obstructive pulmonary disease therapeutics. Proc Am Thorac Soc 2011; 8: 334-337.

28 Troosters T, Sciurba F, Battaglia S, et al. Physical inactivity in patients with COPD, a controlled multi-center pilot-study. Respir Med 2010; 104: 1005-1011.

29 Ofir D, Laveneziana P, Webb KA, et al. Mechanisms of dyspnea during cycle exercise in symptomatic patients with GOLD stage I chronic obstructive pulmonary disease. Am J Respir Crit Care Med 2008; 177: 622-629.

30 Garcia-Aymerich J, Lange P, Benet M, et al. Regular physical activity modifies smoking-related lung function decline and reduces risk of chronic obstructive pulmonary disease: a population-based cohort study. Am J Respir Crit Care Med 2007; 175: 458-463.

31 Hopkinson NS, Polkey MI. Does physical inactivity cause chronic obstructive pulmonary disease? Clin Sci (Lond) 2010; 118 565-572.

32 Garcia-Rio F, Lores V, Mediano O, et al. Daily physical activity in patients with chronic obstructive pulmonary disease is mainly associated with dynamic hyperinflation. Am J Respir Crit Care Med 2009; 180: 506-512.

33 Pellegrino R, Viegi G, Brusasco V, et al. Interpretative strategies for lung function tests. Eur Respir J 2005; 26: 948-968. 
34 Hannink JD, van Helvoort HA, Dekhuijzen PN, et al. Dynamic hyperinflation during daily activities: does COPD global initiative for chronic obstructive lung disease stage matter? Chest 2010; 137: 1116-1121.

35 O'Donnell DE, Guenette JA, Maltais F, et al. Decline of resting inspiratory capacity in COPD: the impact on breathing pattern, dyspnea and ventilatory capacity during exercise. Chest 2012; 141 : 753-762.

36 Montes de Oca M, Loeb E, Torres SH, et al. Peripheral muscle alterations in non-COPD smokers. Chest 2008; 133: 13-18.

37 van den Borst B, Koster A, Yu B, et al. Is age-related decline in lean mass and physical function accelerated by obstructive lung disease or smoking? Thorax 2011; 66: 961-969.

38 Gosker HR, Zeegers MP, Wouters EF, et al. Muscle fibre type shifting in the vastus lateralis of patients with COPD is associated with disease severity: a systematic review and meta-analysis. Thorax 2007; 62: 944-949.

39 Castillo Martinez L, Colin Ramirez E, Orea Tejeda A, et al. Bioelectrical impedance and strength measurements in patients with heart failure: comparison with functional class. Nutrition 2007; 23: 412-418.

40 O'Sullivan C, Bentman S, Bennett K, et al. Rehabilitative ultrasound imaging of the lower trapezius muscle: technical description and reliability. J Orthop Sports Phys Ther 2007; 37: 620-626.

41 Gerovasili V, Stefanidis K, Vitzilaios K, et al. Electrical muscle stimulation preserves the muscle mass of critically ill patients: a randomized study. Crit Care 2009; 13: R161.

42 Waschki B, Spruit MA, Watz H, et al. Physical activity monitoring in COPD: compliance and associations with clinical characteristics in a multicenter study. Respir Med 2012; 106: 522-530. 